\title{
TRABAJO DOCENTE Y NUEVA GESTIÓN PÚBLICA EN CHILE: UNA REVISIÓN DE LA EVIDENCIA*
}

\author{
Cristian Oyarzún Maldonado ${ }^{1}$ \\ Rodrigo Cornejo Chávez ${ }^{2}$
}

\begin{abstract}
RESUMEN: El artículo presenta una revisión de alcance de la literatura sobre trabajo docente y Nueva Gestión Pública en Chile a partir de 48 investigaciones publicadas en el periodo 2008-2018. La revisión permitió identificar cuatro líneas de investigación, estas son: "análisis de marcos regulatorios y prescripciones del trabajo docente" (7 estudios); "investigaciones sobre implementación de políticas gerenciales" (16 estudios); "subjetividad docente y políticas gerenciales” (15 estudios); y "estudios sobre validez de instrumentos de política" (10 estudios). Como consideraciones finales se expone una síntesis valorativa acerca de las cuatro categorías identificadas, sus enfoques metodológicos y principales hallazgos, a la vez que se señalan brechas de conocimiento y desafíos para futuras investigaciones.
\end{abstract}

Palabras-claves: Trabajo docente. Nueva Gestión Pública. Modelo escolar chileno. Revisión de alcance de literatura.

\section{TEACHING WORK AND NEW PUBLIC MANAGEMENT IN CHILE: A REVIEW OF THE EVIDENCE}

\begin{abstract}
The article presents a scoping review of the literature on teaching work and New Public Management in Chile from 48 researches published in the period from 2008 to 2018 . The review allowed identifying four lines of research, as follows: "analysis of regulatory frameworks and prescriptions of the teaching work" (7 studies); "research on the implementation of managerial policies" (16 studies); "teacher subjectivity and managerial policies" (15 studies); and "studies on the validity of policy instruments" (10 studies). As final considerations, an evaluative synthesis is exposed about the four identified categories, their methodological approaches and main findings, while pointing out knowledge gaps and challenges for future research.
\end{abstract}

Keywords: Teaching work. New Public Management. Chilean school model. Scoping review of literature.

\footnotetext{
*Esta investigación deriva del proyecto FONDECYT N. 1180801, “Dimensiones emocionales del trabajo docente: regulaciones, experiencias y saberes”, apoyado y financiado por el Consejo Nacional de Investigación Científica y Tecnológica del Estado de Chile.

1.Universidad de Chile - Departamento de Psicología - Facultad de Ciencias Sociales - Santiago, Chile. E-mail: cristian.oyarzunm@usach.cl 2.Universidad de Chile - Departamento de Psicología - Facultad de Ciencias Sociales - Santiago, Chile. E-mail: rodrigo.cornejo@uchile.cl
} 


\title{
TRABALHO DOCENTE E NOVA GESTÃO PÚBLICA NO CHILE: UMA REVISÃO DAS EVIDÊNCIAS
}

\begin{abstract}
RESUMO: Este artigo apresenta uma revisão de escopo da literatura sobre o trabalho docente e a Nova Gestão Pública no Chile, a partir de 48 estudos publicados no período de 2008 a 2018. Tal revisão possibilitou a identificação de quatro linhas de pesquisa, quais sejam: "análise de marcos reguladores e prescrições de trabalho docente" (7 estudos); "pesquisas sobre a implementação de políticas de gestão" (16 estudos); "subjetividade docente e políticas de gestão" (15 estudos); e "estudos sobre a validade dos instrumentos políticos" (10 estudos). Como considerações finais, expomos uma síntese valorativa sobre as quatro categorias identificadas, seus enfoques metodológicos e achados principais, ao mesmo tempo que apontamos lacunas de conhecimento e desafios para pesquisas futuras.
\end{abstract}

Palavras-chave: Trabalho docente. Nova Gestão Pública. Modelo escolar chileno. Revisão de escopo de literatura.

\section{Introducción}

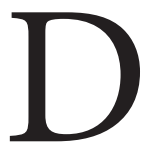

urante las últimas décadas, el mundo ha experimentado transformaciones profundas en el modo de organizar los sistemas escolares de masas y el trabajo docente. Muchos de estos cambios se originan en las críticas a los modelos burocráticos de gobernanza escolar del siglo XX, a lo que prosiguió la difusión a nivel global de la Nueva Gestión Pública (NGP), un modelo de gobernanza promovido por organismos internacionales y que actualmente se aplica en varios países latinoamericanos (NORMAND et al., 2018).

La NGP, también llamada gestión pública neoliberal (MINTROP, 2018) o gerencialismo (BALL, 2003), refiere a un programa de reforma del sector público, cuyo objetivo es optimizar el rendimiento general de las instituciones públicas mediante la aplicación de conocimientos y técnicas de gestión de la empresa privada (BALL; YOUDELL, 2008). Específicamente, la NGP comprende una serie de medidas que incluyen: mercados, descentralización administrativa, autonomía limitada, estandarización de prácticas, metrización de resultados, accountability de alto impacto, flexibilización laboral, incentivos salariales por desempeño y modelos simbólicos de emprendimiento individual (ALVESSON, 2008; ANDERSON; COHEN, 2015; HALL et al., 2015).

En Chile, la adopción de políticas educativas gerenciales presenta dos características disímiles del resto de casos nacionales. Por un lado, estas regulaciones se implementaron en un sistema escolar altamente privatizado, fundado en políticas de mercado aplicadas desde inicios de la década de 1980 (OCDE, 2004). Por otro lado, la NGP es introducida mediante leyes que, paradójicamente, decían "desmercantilizar" la educación escolar y responder a las masivas protestas ciudadanas acaecidas desde el año 2006 en adelante (ASSAÉL et al., 2015; VERGER; NORMAND, 2015).

Estudios recientes identifican patrones comunes asociados a una difusión global de políticas, pero también plantean que los modelos gerenciales varían según los contextos sociales, históricos y políticos de cada Estado (VERGER; NORMAND, 2015; HOLLOWAY et al., 2017). De tal forma que, si bien existe evidencia internacional sobre el impacto de las regulaciones de la NGP en el trabajo docente (v.g., TSANG, 2014; HERR, 2015), es necesario analizar la producción académica disponible 
en Latinoamérica y en particular sobre el extremo caso chileno.

Este artículo expone una revisión de literatura que tuvo como objetivos identificar las líneas de investigación desarrolladas sobre trabajo docente y NGP en Chile y, consiguientemente, describir los principales hallazgos empíricos existentes en la materia. Las preguntas guías de la investigación fueron:

- ¿Qué líneas de investigación se han desarrollado en Chile para estudiar la adopción e implementación de mecanismos de NGP en el ámbito del trabajo docente?

- ¿Cuáles son los principales resultados reportados por la investigación reciente sobre trabajo docente y NGP en Chile?

- ¿Qué brechas o lagunas de conocimiento sugieren los resultados del corpus de investigaciones sobre trabajo docente y NGP en Chile?

Para responder a los objetivos y las preguntas de investigación se realizó un tipo de revisión denominada revisión de alcance -o scoping review - de la literatura, cuyos propósitos son mapear la evidencia disponible acerca de un área o tema de investigación emergente, resumir sus principales resultados e identificar las brechas de conocimiento (ARKSEY; O'MALLEY, 2005; MUNN et al., 2018).

Antes de describir detalladamente la metodología y presentar los resultados, revisaremos brevemente el marco general de las políticas educativas y docentes en Chile, las bases conceptuales de la NGP y la evidencia global sobre su impacto en el trabajo docente.

\section{Antecedentes Contextuales y Teóricos}

\section{Políticas educativas y regulaciones docentes en Chile}

El modelo educativo chileno es mundialmente reconocido como el resultado de la aplicación sistemática de políticas extremas de privatización, mercantilización y competencia (OCDE, 2004; ASSAÉL et al., 2015; CORNEJO, 2018). Las bases de este modelo fueron instituidas durante la dictadura cívico-militar, en la década de los '80, mediante tres transformaciones radicales.

Primeramente, en 1981 se promulgó una Constitución Política que transformó el rol del Estado, de garante a subsidiario de la educación, y consagró el libre emprendimiento privado como el principal derecho educativo (ASSAÉL; CORNEJO, 2018). En segundo lugar, se creó la figura del "sostenedor educativo", un ente -público o privado- con potestad absoluta para: administrar las escuelas, gestionar la subvención estatal, y definir contratos laborales y ajustes curriculares. Desde entonces, los municipios han ejercido como sostenedores de las escuelas que antes administraba el Estado, todo esto en un contexto de trato igualitario con las escuelas privadas. En tercer lugar, se introdujo un modelo de financiamiento de subsidio a la demanda, que traspasa subvención estatal a los sostenedores - públicos o privados- en razón de la asistencia promedio de cada escuela (ASSAÉL et al., 2015).

En la década de los '90, instituciones financieras internacionales y algunos sectores políticos de Chile y Latinoamérica difundieron este modelo como "un ejemplo a seguir" en la región. Empero, hacia el cambio de siglo quedó en evidencia que este modelo generaba privatización extrema, deterioro de la educación pública, segmentación socioeducativa y falta de pertinencia curricular (ASSAÉL et al., 2015). Estas críticas surgieron de actores disímiles: por un lado, la OCDE emitió un lapidario informe que señalaba, entre otras críticas, que "el sistema escolar chileno está conscientemente estructurado 
por clases sociales" (OCDE, 2004, p. 277); y, por otro lado, los estudiantes de educación secundaria protestaron por lo que ellos consideraban una mala educación, protagonizando masivas protestas nacionales en el año 2006 (GONZÁLEZ et al., 2008).

Después del año 2006, se promulgó una decena de leyes que pretendían responder a las críticas del modelo, en algunos casos intentando hacer que el mercado educativo funcione de manera más justa y en otros buscando sacar la educación de la esfera del mercado. Por ejemplo, entre los años 2008 y 2011 se aprobaron cuatro leyes que modifican el marco regulatorio del sistema escolar y, por ende, también del trabajo docente: la Ley de Subvención Escolar Preferencial (SEP) (CHILE, 2008), que entrega subsidio adicional a los sostenedores - privados o municipales- para atender estudiantes en condición de pobreza; la Ley General de Educación (LGE) (CHILE, 2009), que da un marco global al conjunto de nuevas regulaciones sin alterar lo instituido en la Constitución de 1981; la Ley de Calidad y Equidad (LCyE) (CHILE, 2011a), que flexibiliza las condiciones del trabajo docente y proporciona un rol gerencial a los directores; y la Ley de Aseguramiento de la Calidad de la Educación (SAC) (CHILE, 2011b), que crea las instituciones -anunciadas en la LGE- para fijar, evaluar y fiscalizar los estándares de calidad educativa: Consejo Nacional de Educación, Agencia de Calidad y Superintendencia de Educación. No obstante, según varios investigadores estas leyes introdujeron y consolidaron la NGP en la educación escolar chilena (CARRASCO, 2013; VERGER; NORMAND, 2015; ASSAÉL; CORNEJO, 2018; CORNEJO, 2018).

En el caso puntual de las políticas docentes, también se evidencia un proceso de privatización y sucesivas reformas con resultados contradictorios. Durante la dictadura, el gremio docente fue duramente perseguido y reprimido, debiendo enfrentar una fuerte precarización laboral. Efectivamente, hasta el golpe de Estado del año 1973 la mayoría de los docentes chilenos eran funcionarios públicos dependientes del Ministerio de Educación. Luego, en el marco de la privatización y municipalización escolar, pasaron a regirse por el código laboral privado, cambio que "significó importante pérdida de conquistas (condiciones de ingreso, remuneraciones, estabilidad laboral, deberes y derechos, sistema de jubilación por años de servicio), y absoluta flexibilidad laboral" (ASSAÉL; CORNEJO, 2018, p. 248).

Durante el primer gobierno de postdictadura -en 1991- se promulgó un Estatuto Docente. Esta ley representó un avance en relación con la desprotección extrema instaurada en los años '80, sin embargo, conservó un régimen laboral dual entre los profesores que laboran en el sistema municipal y aquellos que lo hacen en el sector particular subvencionado, situación vigente hasta la fecha (ASSAÉL; CORNEJO, 2018). Posteriormente, el Estatuto Docente ha sufrido varias modificaciones en la línea de aumentar la flexibilización laboral. Como ejemplo de esto, se tiene la Ley n. 19.961 Sobre Evaluación Docente (CHILE, 2004), cuestionada por el magisterio debido a su carácter predominantemente sumativa, y porque indujo una sobrecarga laboral ante la falta de condiciones adecuadas para efectuar el proceso evaluativo (ÁVALOS, 2017).

En el año 2011, los estudiantes chilenos vuelven a protagonizar una masiva y, esta vez, prolongada protesta contra el mercado educativo. Nuevamente, la elite chilena acordó realizar ajustes al modelo. Para ello, en el periodo 2014-2017 se aprobaron tres leyes sobre el sistema escolar y el trabajo docente: la Ley n 20.845 de Inclusión Escolar, que regula el funcionamiento de los sostenedores privados financiados estatalmente e incrementa el monto de subvención que se transfiere a este tipo de sostenedores (CHILE, 2015); la Ley n. 21.040 que Crea el Sistema de Educación Pública, la cual cambia el sistema de administración municipal de la educación pública (CHILE, 2017); y la Ley n. 20.903 que Crea el Sistema Nacional de Desarrollo Profesional Docente (CHILE, 2016), que, fundamentalmente, introdujo regulaciones a la formación del profesorado e instaló un gran dispositivo nacional de evaluación individual del desempeño docente, en función de parámetros estandarizados y con consecuencias de alto impacto (CORNEJO; CARO, 2015; RUFFINELLI, 2016; ÁVALOS, 2017). 
Esta última ley fue altamente polémica, pues algunos sectores consideraron que constituía un avance en relación con las precarias condiciones laborales del profesorado, mientras que para otros dañaba el profesionalismo docente limitándolo al individualismo, la estandarización, la competencia y las variaciones salariales asociadas al desempeño.

\section{La Nueva Gestión Pública en la Agenda Educativa Global}

La difusión de la NGP se enmarca en una agenda educativa global que busca generar mayor eficiencia y productividad entre los sistemas escolares. Dicha agenda es promovida principalmente desde organismos internacionales, que atribuyen a la educación funciones determinantes en la formación de un capital humano competitivo en el contexto de la actual economía del conocimiento y, por ende, en el crecimiento económico de los países (HOLLOWAY et al., 2017; CARVALHO; NORMAND, 2018).

La expansión de este tipo de políticas es justificada en función de una cantidad suficiente de pruebas empíricas que legitimarían su aplicación a escala mundial (NORMAND et al., 2018). Aun así, no menor es la influencia de factores políticos. En efecto, la difusión de reformas gerencialistas también es favorecida por su carácter transideológico, es decir, la capacidad de generar aceptación entre grupos vinculados a distintas posiciones políticas (VERGER; NORMAND, 2015). Como muestra de aquello, partidos socialdemócratas, y no sólo de orientación neoliberal, suelen incorporarlas en sus programas electorales para captar o retener adherentes, pues ofrecen soluciones concretas y de bajo costo a coyunturas transversales. En este sentido, Verger y Normand (2015, p. 612) afirman que:

las soluciones de NGP en educación no son adoptadas necesariamente porque "funcionan" (de hecho, hay muchos interrogantes empíricos todavía abiertos al respecto), sino porque existe una percepción generalizada de que son políticas que podrían solucionar una parte importante de los problemas más apremiantes.

Consiguientemente, la NGP emplea recursos ideacionales que transmiten certidumbres sobre el funcionamiento y la productividad de los sistemas escolares. En este sentido, Gleeson y Knights (2006) explican que la racionalidad detrás de la NGP en educación refiere a prescribir el proceso de enseñanza mediante el uso de instrumentos exógenos que tipifican prácticas, cuantifican rendimientos y castigan o premian resultados, para asegurar que los desempeños se ajusten a las metas definidas en la política y evitar la corrosión del sistema producto de intereses personales y/o gremiales.

En base a lo expuesto, es importante considerar que las políticas públicas operan como discursos hegemónicos que, si bien no determinan las conductas de los actores, representan categorías semánticas que imponen formas de pensar y hacer acerca de una actividad profesional (ANDERSON; COHEN, 2015). Desde esta perspectiva, se infiere la influencia de la NGP en las actuales transformaciones que experimentan los profesores y su trabajo.

\section{El Impacto de las Políticas Gerenciales en la Docencia}

En diversos contextos nacionales se han reportado variados efectos contraproducentes que las políticas manageriales generarían sobre la docencia, especialmente cuando utilizan consecuencias de alto impacto. Puntualmente, se han identificado: 
- Procesos de desprofesionalización y pérdida de autonomía derivados de las fuertes prescripciones de este tipo de políticas (BALL, 2003; HERR, 2015; MINCU, 2018);

- Empobrecimiento de la enseñanza ante la exacerbada preocupación por los resultados de evaluaciones estandarizadas con consecuencias de alto impacto (DARLING-HAMMOND, 2014; VAN DER SLUIS et al., 2017);

- Utilización de modelos de emprendimiento individual basados en incentivos económicos que incitan la competencia e inhiben la colaboración (GEWIRTZ; BALL, 2000; MINTROP, 2018);

- Elevados niveles de desgaste emocional (TSANG; KWONG, 2016) y sentimientos de culpa, ansiedad y pérdida de sentido asociados a la intensificación laboral (TSANG, 2014; CHEN, 2016);

- Los docentes desarrollan perspectivas críticas sobre los dispositivos de evaluación, pues éstos no incluyen conocimientos y habilidades que el profesorado considera relevantes para su trabajo (DE GAULEJAC, 2007). Dichas discrepancias tienden a generar procesos de desafección y resistencia por parte de los maestros ante las prescripciones de la política (KELCHTERMANS, 2005; HERR, 2015).

\section{Metodología}

Esta investigación se basa en un enfoque metodológico denominado revisión de alcance o scoping review (ARKSEY; O'MALLEY, 2005). La revisión de alcance es un tipo de revisión que consiste en mapear la producción científica sobre un tema con el fin de sintetizar sus principales hallazgos e identificar brechas de conocimiento, siendo especialmente útil cuando el propósito es explorar la evidencia disponible y proporcionar una visión general respecto de un tópico de investigación emergente (LEVAC; COLQUHOUN; O`BRIEN, 2010; MUNN et al., 2018).

La revisión de alcance dispone de un procedimiento que permite replicar la estrategia de búsqueda y aporta confiabilidad a los resultados del estudio (O’FLAHERTY; PHILLIPS, 2015). Al respecto, utilizamos el marco procedimental propuesto por Arksey y O’Malley (2005) que incluye cinco etapas:

- Identificar los objetivos y las preguntas de la investigación -señaladas en la sección introductoria;

- Identificar publicaciones sobre la temática estudiada;

- Seleccionar publicaciones empíricas relevantes para los objetivos y las preguntas de investigación;

- Analizar, categorizar e interpretar los datos; y

- Organizar, resumir y reportar los principales hallazgos de la revisión.

En cuanto a la etapa de identificación de publicaciones, se elaboró una fórmula de búsqueda o sintaxis que combinó palabras claves relacionadas con "trabajo docente", "Chile" y diversas acepciones empleadas para denominar la NGP y sus dispositivos, como, por ejemplo, "managerialismo", "accountability", "pago por mérito", entre otros. La búsqueda fue realizada en las bases de datos WoS/ SciELO y SCOPUS. Complementariamente, para evitar pérdidas de literatura relevante, se llevó a cabo una búsqueda en otras bases de datos como ERIC, Redalyc, Dialnet y Google Scholar. Es importante 
señalar que, el uso de bases de datos diferentes a WoS/SciELO y SCOPUS se fundamenta en los propósitos de la revisión de alcance, que -como mencionamos más arriba- refieren a mapear toda la evidencia empírica disponible y organizar el debate académico en torno a un tema (MUNN et al., 2018).

Cabe puntualizar que, la identificación de literatura se restringió a publicaciones emitidas en el periodo 2008 - 2018. Este límite temporal constituye un lapso prudente para revisar el conocimiento acumulado en la materia. Además, el año 2008 fue promulgada la SEP que, según varios autores, inaugura la aplicación articulada de la NGP en Chile (CARRASCO, 2013; FALABELLA, 2015; ASSAÉL; CORNEJO, 2018). Además, es menester consignar que el objeto de interés de esta revisión se centró en dispositivos de NGP que regulan el trabajo docente tanto a nivel organizacional ( $v . g$., SAC) como individual ( $v . g$., Sistema de Evaluación Docente).

Por su parte, en la etapa de selección de literatura sólo se incorporaron publicaciones que reportan hallazgos de investigaciones -cualitativas o cuantitativas- sobre trabajo docente y NGP en Chile, excluyéndose ensayos, artículos teóricos, tesis de postgrado o ponencias. Con todo, la muestra final incluyó 48 publicaciones empíricas. La Fig. 1 expone el flujograma de identificación, selección e inclusión de artículos.

Posteriormente, durante la etapa de análisis, categorización e interpretación de los datos, las publicaciones de la muestra fueron sintetizadas en fichas que incluían tres ítems: objetivo de investigación, resultados y conclusiones. Luego, cada resumen fue analizado inductivamente para identificar su tema central de investigación. Por último, se procedió a comparar iterativamente los temas de investigación asociados a cada publicación, proceso que permitió identificar similitudes entre temas y agruparlos en categorías. De este modo, se identificaron cuatro categorías: "Análisis de marcos regulatorios y prescripciones del trabajo docente" (7 estudios); "Investigaciones sobre implementación de políticas gerenciales" (16 estudios); "Subjetividad docente y políticas gerenciales" (15 estudios); y "Estudios sobre validez de instrumentos de política" (10 estudios). Las referencias bibliográficas de los artículos incluidos en la revisión están detalladas en la sección de referencias, mientras que la sintaxis de búsqueda empleada se encuentra disponible en el siguiente repositorio: https://osf.io/na7s8/.

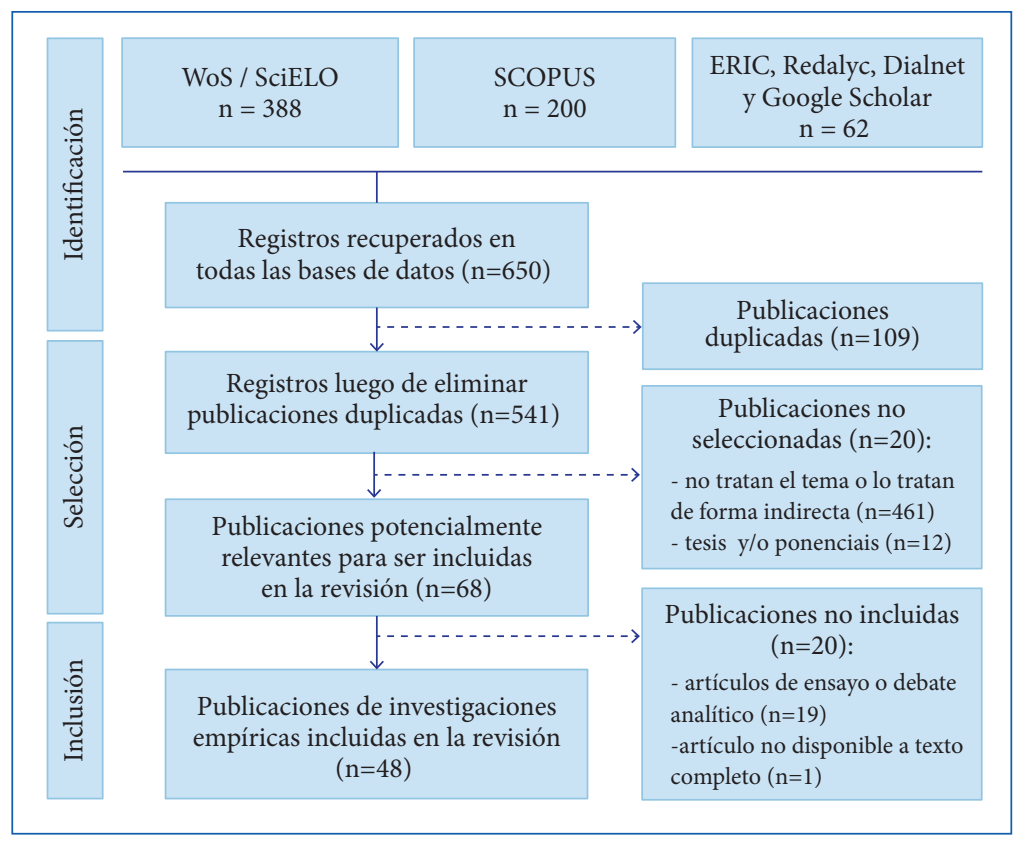

Figura 1. Diagrama de flujo de identificación, selección e inclusión de artículos. 
A continuación, presentaremos la sección de resultados, en ella se examinarán en detalle las cuatro categorías en base a las 48 investigaciones seleccionadas.

\section{Resultados}

\section{Análisis de marcos regulatorios y prescripciones del trabajo docente}

Las siete investigaciones que integran esta categoría se caracterizan por presentar análisis empíricos sobre marcos legales y documentos oficiales promulgados en el periodo 2003-2015, los cuales introducen importantes procesos de modernización de la gestión escolar y la profesión docente en Chile.

El hallazgo principal de estos estudios refiere a la existencia de una noción específica sobre la docencia, promovida por las políticas de tipo gerencial. Los estudios seleccionados coinciden en que estos marcos normativos definen al docente como un profesional que ejecuta prácticas estandarizadas para lograr resultados académicos mensurables y cuyo desempeño es regulado mediante recompensas y sanciones (SISTO; FARDELLA, 2011; FARDELLA, 2012; BISCARRA et al., 2015; CORNEJO et al., 2015; FERNÁNDEZ et al., 2016; SOTO et al., 2016; ETCHEBERRIGARAY et al., 2017). En este contexto, las investigaciones revisadas puntualizan que dicha noción se establece indirectamente a través de prescripciones y condiciones laborales basadas en lineamientos propios de la NGP. En otras palabras, se instaura una intensa estandarización de procesos y resultados, accountability de alto impacto y medidas de flexibilización laboral (CORNEJO et al., 2015; FERNÁNDEZ et al., 2016; ETCHEBERRIGARAY et al., 2017).

De forma específica, tres publicaciones analizan lo que sus autores llaman el "nuevo marco regulatorio de la educación escolar chilena" (CORNEJO et al., 2015; FERNÁNDEZ et al., 2016; ETCHEBERRIGARAY et al., 2017), conformado por una serie de leyes promulgadas entre 2008 y 2011, que incluyen la SEP, el SAC y la LCyE. Estas investigaciones concluyen que las políticas mencionadas representan una consolidación a nivel sistémico de la perspectiva gerencial, excluyéndose cualquier versión alternativa de docencia (CORNEJO et al., 2015); asimismo, se caracterizan por imponer una noción de autonomía limitada, que subordina el quehacer cotidiano del profesor al cumplimiento de estándares externos (FERNÁNDEZ et al., 2016); y que, por ende, prepondera en su responsabilidad individual como ejecutor pasivo de dichas prescripciones para alcanzar el "éxito educativo" (ETCHEBERRIGARAY et al., 2017). Ideas similares entregan Biscarra et al. (2015) en un estudio sobre concepciones de la docencia en la legislación educacional chilena. Estas investigadoras analizan el mismo lapso temporal, describiéndolo como un momento de intensificación de reformas educativas neoliberales, fundadas en la estandarización y la gestión orientada a resultados, lo que a su juicio empobrece el profesionalismo de los maestros, reduciéndolo a una adscripción irrestricta al modelo y sus prescripciones.

Las restantes investigaciones refrendan la concepción de docencia descrita y agregan hallazgos en torno a estrategias discursivas de justificación y difusión de las políticas gerenciales. En esta línea, Sisto y Fardella (2011) analizan documentos oficiales sobre fortalecimiento de la profesión docente, identificando el uso de una retórica epocalista, alusiva a un discurso que ilustra la oposición entre un periodo actual de déficit y una única vía efectiva de mejoramiento: la NGP. Esto es complementado por el estudio de Fardella (2012), quien concluye que el modelo de profesionalidad 
propuesto por las políticas se presenta como la única forma eficiente para ejercer la docencia, y también por la investigación de Soto et al. (2016), quienes encuentran que la promoción de un perfil de docente efectivo es acompañada de un discurso que pretende lograr adhesión apelando al compromiso emocional de los profesores con su trabajo.

\section{Investigaciones Sobre Implementación de Políticas Gerenciales}

La segunda categoría congrega dieciséis investigaciones que han centrado su interés en describir y comprender los procesos de implementación de las políticas gerencialistas y sus efectos en la gestión escolar y la docencia. En esta categoría identificamos dos subgrupos de investigaciones, el primero analiza la implementación y consecuencias de políticas manageriales a nivel organizacional (v. g., SAC o SEP), mientras que el segundo lo hace a nivel individual (v. g., Sistema de Evaluación Docente y sus dispositivos).

En el primer subgrupo encontramos la investigación de Elacqua et al. (2015), quienes analizaron el efecto de la SEP y sus consecuencias sobre las políticas y prácticas de los docentes pertenecientes a escuelas categorizadas "en recuperación". ${ }^{1}$ Los principales resultados indican que las escuelas de bajo rendimiento responden implementando políticas institucionales orientadas a incrementar el rendimiento académico de los estudiantes en un corto plazo, como pruebas de selección múltiple y programas de evaluación. Dichas políticas serían implementadas de "arriba hacia abajo", sin la participación de los maestros, y en ningún caso conllevarían una modificación sustantiva o innovación a nivel de las prácticas pedagógicas. Por último, Elacqua y sus colaboradores concluyen acerca de la necesidad de realizar estudios cualitativos que describan las prácticas empleadas en escuelas bajo amenaza de cierre.

Consiguientemente, algunos equipos de investigación se han interesado en comprender cualitativamente el impacto de las políticas de corte gerencial. Este es el caso de las etnografías de Acuña et al. (2014) y Assaél et al. (2014), cuyo objetivo fue conocer la traducción, esto es la interpretación y actuación, que comunidades educativas pertenecientes a zonas pobres realizan de la ley SEP, que en el sistema escolar chileno introdujo mecanismos de accountability y rankings de desempeño a nivel de las escuelas. Sus hallazgos apuntan a que esta política genera una exacerbada relevancia en torno a los resultados del SIMCE, ${ }^{2}$ lo que se traduce en: sentimientos de desmoralización ante las dificultades para alcanzar "mejoras" en los indicadores de desempeño; acciones tendientes a producir evidencia para satisfacer los requerimientos de rendición de cuentas, en desmedro de labores netamente pedagógicas; y juicios negativos acerca de los dispositivos de apoyo estatales, que califican como insuficientes.

En una línea investigativa similar ubicamos los estudios de caso. Al respecto, Assaél et al. (2012) presentan dos estudios de caso sobre la implementación de la ley SEP y su impacto en el trabajo docente, reportando que estos actores perciben la responsabilización por desempeño en términos de culpabilización individual y que los distintos mecanismos de accountability propenden hacia una pérdida de autonomía, siendo entendidos como un proceso de desprofesionalización de la docencia. Por su parte, Falabella $(2014 ; 2016)$ estudió el SAC y la sofisticación de los rankings de desempeño, encontrando que esta política guía el funcionamiento de las escuelas mediante una racionalidad instrumental centrada en lograr resultados estandarizados y auditables, los que en función de su carácter coercitivo definen el sentido del trabajo educativo. Esta dinámica genera efectos nocivos 
en escuelas con bajos resultados y que atienden a poblaciones vulnerables, las cuales articulan su gestión en torno a acciones para responder a las presiones de la política, pero no instalando procesos de mejoramiento ni fortaleciendo sus prácticas pedagógicas.

La revisión también permitió identificar evidencia acerca de la implementación de dispositivos manageriales específicos, como el uso de incentivos monetarios ligados a incrementos en los resultados de pruebas estandarizadas. Con más detalle, Contreras y Rau (2012) efectuaron una investigación dirigida a estimar el efecto de un programa de incentivos colectivos ${ }^{3}$ en la población de escuelas participantes. A partir de sus hallazgos, los autores afirman que el SNED ha tenido efectos positivos sobre los puntajes de lenguaje y matemáticas del SIMCE, y, por añadidura, en el desempeño de los profesores. No obstante, advierten que este sistema de incentivos sólo aumenta la productividad de una fracción específica de escuelas, sobre todo en aquellas con una probabilidad de ganar ex ante mayor que el percentil 60 .

En cuanto al segundo subgrupo, que trata la implementación y efectos del Sistema Nacional de Evaluación Docente, se encontraron nueve investigaciones. En términos generales, la evidencia recopilada señala que la información proporcionada por el sistema de evaluación dispone de escasa utilidad formativa, constituyéndose en un mecanismo de rendición de cuentas para certificar competencias mínimas y no una instancia de desarrollo profesional, y que, por consiguiente, no incide de forma significativa en los resultados de aprendizaje del alumnado (SANTIAGO et al., 2013; VEGA; GALAZ, 2015; VAILLANT; GONZALEZ-VAILLANT, 2016; ROA-TAMPE, 2017; OCDE, 2017).

Algunas investigaciones pesquisadas indagan en aspectos y dispositivos específicos del Sistema Nacional de Evaluación Docente. Por ejemplo, Sisto et al. (2013) contrastan concepciones de docencia emanadas de políticas locales desarrolladas por administradores escolares de dos municipios con la política nacional de evaluación docente. Los principales resultados señalan que ambos niveles el local y el nacional- tienden a superponerse y a entrar en disputa, mientras que desde la perspectiva de los profesores se manifiesta poca adhesión a las políticas locales y a nivel nacional sólo valoran aquellas instancias que permiten la reflexión pedagógica con otros colegas. Por su parte, Montecinos et al. (2014) indaga en un dispositivo concreto del sistema evaluativo: la Red Maestros de Maestros (RMM), un programa que reconoce a los docentes mejor evaluados permitiéndoles ofrecer servicios de asesoramiento a colegas de bajo desempeño en una modalidad de consultoría. Los hallazgos revelan que el estatus asignado mediante este reconocimiento socava el capital social del profesorado, pues la estratificación genera un problema de validación y rechazo entre los participantes de los talleres de la RMM, que lleva a los tutores a utilizar prácticas discursivas para ocultar su estatus y reposicionarse como pares ante sus colegas.

Finalmente, otros trabajos de investigación se han centrado -aunque todavía de modo incipiente- en los incentivos monetarios de carácter individual que forman parte del sistema de evaluación docente. En este ámbito, la evidencia sugiere que el uso de incentivos monetarios no redunda en mejoras de la calidad educativa, pues éstos implican un compromiso burocrático de tipo transaccional y no motivan la acción hacia un mejoramiento de las prácticas pedagógicas (VAILLANT, 2012). Además, se ha evidenciado que los profesores chilenos tienen una percepción negativa de los incentivos económicos, especialmente cuando "premian" el desempeño individual, ya que dichos dispositivos son comprendidos como una estrategia destinada a compensar los bajos salarios y las malas condiciones del trabajo docente (ACUÑA, 2015).

En resumen, las publicaciones reseñadas en esta sección indican que, a partir de la implementación sistemática de políticas de corte gerencial a nivel de la gestión o de la evaluación del 
trabajo docente, se generan una serie de efectos no esperados que incluyen procesos de desmoralización en comunidades educativas ubicadas en zonas de pobreza, desprofesionalización de la función docente y escasos incentivos que propendan y apoyen el mejoramiento genuino de la enseñanza.

\section{Subjetividad Docente y Políticas Gerenciales}

Esta categoría agrupa quince investigaciones que analizan la producción de subjetividad docente en un ambiente institucional gerencialista. Específicamente, estas publicaciones buscan describir y comprender los significados que el profesorado atribuye a las tecnologías y dispositivos de este tipo de políticas; así como las tensiones en el ejercicio de la docencia y los relatos identitarios laborales que emergen en contextos gerenciales.

Respecto de esta temática se identificaron dos hallazgos principales: una significativa diferencia entre el contenido del trabajo docente prescrito y los sentidos que adquiere la docencia en contextos socioeducativos reales (ÁVALOS; DE LOS RÍOS, 2013; CAMPOS et al., 2013; ROJAS; LEYTON, 2014; QUARESMA; ORELLANA, 2016; CASTILLO et al., 2017; FERRADA, 2017; REYES; AKKARI, 2017); y la ocurrencia de respuestas subjetivas, que incluyen formas de adscripción y/o de resistencia de diversa índole (SISTO, 2011; 2012; FARDELLA, 2013; FARDELLA; SISTO, 2015; GUERRERO, 2017; GUERRERO et al., 2017).

El primer hallazgo es tratado de forma directa en siete estudios. En términos generales, las transformaciones impulsadas por las políticas de accountability son comprendidas como intentos de imponer "nuevas" y "mejores" prácticas desde el exterior, posicionando a los docentes como agentes pasivos y desprovistos de saber pedagógico (ROJAS; LEYTON, 2014). De forma más específica, algunos estudios han contrastado la concepción de enseñanza inducida desde estas políticas con los juicios del profesorado, encontrándose que en zonas de pobreza la "buena enseñanza" se asocia con la capacidad de gestionar la convivencia y las necesidades sociales de la comunidad, lo cual supera el ideal oficial de calidad vinculado únicamente con la obtención de resultados en pruebas estandarizadas (ÁVALOS; DE LOS RÍOS, 2013; CAMPOS et al., 2013; FERRADA, 2017; REYES; AKKARI, 2017). Dinámicas similares se hallan en otros contextos, tal es el caso que maestros de sectores rurales califican los contenidos e instrumentos del sistema de evaluación docente como poco atingentes a su realidad (CASTILLO et al., 2017); mientras que, en liceos públicos de alto rendimiento, los profesores otorgan sentido a su labor por medio de valores éticos distintos a aquellos de carácter instrumental promovidos por las políticas de accountability (QUARESMA; ORELLANA, 2016).

Por su parte, seis publicaciones indagan en las respuestas subjetivas que surgen ante las políticas gerenciales. En este sentido, Fardella y Sisto (2015) describen una adscripción subjetiva, es decir, una adhesión instrumental a las prácticas de la política, y variadas formas de resistencia como malestar, demandas de reconocimiento y cuestionamiento a las categorías oficiales. Esto es profundizado en el trabajo de Fardella (2013), quien identifica cuatro taxonomías de prácticas subjetivas que incluyen: actuación y representación, semejante a la adscripción subjetiva; prácticas de escamoteo o realización disimulada de acciones irregulares, como la adquisición de portafolios pagados para la evaluación docente; rumores, cuyo propósito es desprestigiar la política; y fantasías de dominación referidas a narraciones sobre conocimiento de los cánones operativos de la política, que finalmente derivan en el uso de prácticas para superar las exigencias de la evaluación. 
Las publicaciones de Sisto $(2011 ; 2012)$, además de describir esta dicotomía y las respuestas subjetivas derivadas, aportan hipótesis comprehensivas sobre la ocurrencia de dichos fenómenos. Sus hallazgos plantean que las políticas, en particular la evaluación docente, propenden hacia una forma nueva de profesionalismo basada en el logro individual de estándares y metas medibles, la que es resistida desde el profesorado pues se trata de elaboraciones de "expertos", quienes en su intento de regular y homogenizar la realidad ignoran los contextos y saberes pedagógicos locales. En contraste, el profesorado resiste al orden impuesto por las políticas apelando a elementos de identidades tradicionales ligadas al servicio público y el compromiso social (SISTO, 2011; 2012). En otras palabras, se instaura una oposición entre las identidades tradicionales y los nuevos paradigmas identitarios, disputa en la cual los docentes defienden un sentido teleológico de su trabajo, más ligado a la justicia social que a la obtención de resultados en pruebas estandarizadas.

Otros estudios han indagado en respuestas subjetivas relacionadas con aspectos afectivos, como el sufrimiento psicológico de los profesores insertos en un ambiente laboral gerencialista. Puntualmente, nos referimos a las investigaciones de Guerrero (2017) y Guerrero et al. (2017), quienes en base a una perspectiva denominada Sociología Clínica del Trabajo analizan los efectos de las políticas sobre la cotidianidad del trabajo docente en contextos de alta vulnerabilidad social. Estos trabajos concluyen que los indicadores de eficiencia propios del management tienden a invisivilizar dimensiones importantes del trabajo cotidiano de los maestros. De este modo, dicha falta de reconocimiento deviene en procesos de subjetivación dolorosos, marcados por la frustración y la desmoralización.

La evidencia más reciente indica que las críticas y resistencias descritas permanecen vigentes, especialmente en relación con la promulgación de la Ley n 20.903 que Crea el Sistema Nacional de Desarrollo Profesional Docente. En particular, un estudio conducido por Jarpa y Castañeda (2018) tuvo como objetivo describir y analizar las representaciones sociales de los profesores respecto de la mencionada ley. Los resultados obtenidos sostienen que el profesorado rechaza la iniciativa por considerarla poco representativa, basada en la desconfianza y de carácter punitivo; adicionalmente, los maestros expresan temores fundados en una posible intensificación de procesos de despedagogización, desprofesionalización y pauperización de sus condiciones laborales, por lo cual demandan una mayor participación en la construcción de este tipo de marcos legales (JARPA; CASTAÑEDA, 2018).

Antes de cerrar esta categoría, es relevante consignar que, siguiendo los estudios del discurso docente, las críticas y resistencias expuestas pueden interpretarse como manifestaciones aisladas y coyunturales, pues aún no están articuladas en un discurso elaborado y propositivo frente al marco institucional imperante. En este sentido, Cornejo e Insunza (2013) plantean que el discurso de los profesores se desarrolla en los márgenes del orden discursivo hegemónico, es decir, utiliza el lenguaje de las políticas para hacerse inteligibles. Por lo tanto, el desacuerdo con la institucionalidad suele ser expresado mediante conceptos del management, mas no mediante un proyecto educativo y social que proponga nuevos sentidos y propósitos sobre el trabajo docente.

\section{Estudios sobre Validez de Instrumentos de Política}

Esta categoría reúne diez publicaciones sobre la validez de los instrumentos evaluativos del Sistema Nacional de Evaluación Docente. Aun cuando estas publicaciones no buscan analizar una política "gerencial", el Sistema Nacional de Evaluación Docente reúne las principales características de la NGP y se 
erige como el principal marco regulatorio del trabajo docente en Chile. Con más detalle, este sistema se basa en estándares de desempeño y evaluación permanente, cuyos resultados están ligados a consecuencias de alto impacto que en la nomenclatura oficial son presentadas como consecuencias formativas -incentivos económicos de tipo individual y oportunidades de perfeccionamiento para quienes logran mejores resultados- y consecuencias sumativas - posibilidades de despido por mal desempeño reiterado-.

El sistema de evaluación se implementó en el año 2004 y tiene cuatro instrumentos que evalúan el grado de ajuste al Marco para la Buena Enseñanza (MBE): autoevaluación, informe de referencia de terceros, entrevista por un evaluador par y portafolio. Los resultados derivan en cuatro categorías correlativas que clasifican el desempeño, así los profesores calificados en nivel destacado acceden, previa realización voluntaria y aprobación de una prueba técnica, al incentivo económico llamado Asignación Variable por Desempeño Individual (AVDI) y tienen la posibilidad de incorporarse a la RMM, mientras quienes logran un nivel insatisfactorio en dos evaluaciones consecutivas pueden ser despedidos (TAUT; SUN, 2014). La reciente Ley de Carrera Docente, a pesar de incorporar una noción de carrera profesional con mejoras remuneracionales, preservó esta matriz evaluativa y, además, enlazó los progresos de carrera a una evaluación que incluye un nuevo portafolio y una prueba de conocimientos curriculares (CHILE, 2016).

La totalidad de los estudios analizados en esta categoría han sido efectuados por MIDE UC, un centro de investigación encargado del diseño e implementación del sistema de evaluación. En el año 2005, MIDE UC comenzó a desarrollar una agenda de investigación comprehensiva sobre la validez de los instrumentos evaluativos. Para evitar un sesgo confirmatorio y siguiendo recomendaciones de la literatura especializada, estas investigaciones utilizan diversos enfoques metodológicos e incorporan múltiples tipos de evidencia, que incluyen estudios sobre: validez de contenido, validez de estructura interna, validez consecuencial y validez convergente/discriminante (TAUT et al., 2011a).

Los estudios sobre validez de contenido sostienen que los instrumentos evaluativos disponen de una apropiada cobertura de los contenidos que conforman el MBE (TAUT et al., 2011a). Sin embargo, la revisión de Taut y Sun (2014) advierte respecto de la falta de validez que exhiben algunos instrumentos en su aplicación, tal es el caso de la autoevaluación y el informe de referencia de terceros, que dispondrían de un considerable potencial de fraude o corrupción reflejado en "puntuaciones infladas". En un sentido similar, Taut et al. (2012) añade precauciones sobre riesgos de corrupción mediante "portafolios pagados".

Las investigaciones sobre validez de estructura interna concluyen que el coeficiente de alfa de Cronbach ${ }^{4}$ ha sido alto y estable en el tiempo, al menos en tres instrumentos: portafolio, informe de referencia de terceros y entrevista por un par evaluador (TAUT et al., 2011a). En el periodo 2008-2010, también se efectuaron estudios de generalizabilidad de los resultados del portafolio, encontrándose que la varianza atribuible a los correctores externos representaba porcentajes pequeños -3\% a $10 \%-$, concluyéndose que los resultados de este instrumento logran adecuados niveles de confiabilidad, pues el efecto no deseado del evaluador es generalmente bajo (TAUT et al., 2011a; TAUT et al., 2012).

Por su parte, los estudios de validez consecuencial, que buscan corroborar la teoría de la acción subyacente a un programa evaluativo, han entregado evidencia sobre consecuencias previstas y emergentes observadas por los actores educativos que participan en la evaluación. Sus principales hallazgos indican que: la evaluación ha alcanzado parcialmente las consecuencias intencionadas en materias como entrega de apoyo a profesores de bajo desempeño, adhesión al AVDI, promoción del trabajo colaborativo y uso efectivo de información por parte de los empleadores (SANTELICES et al., 2013); existe divergencia en las teorías elaboradas por los distintos actores -Colegio de Profesores, funcionarios del Ministerio de Educación y Asociación de Municipios-, especialmente 
en cuanto a las consecuencias esperadas (TAUT et al., 2010; TAUT et al., 2011b); finalmente, se han identificado resistencias de algunos profesores a participar voluntariamente en la evaluación a raíz de cuestionamientos a la legitimidad del sistema y por la ocurrencia de emociones negativas ante eventuales resultados deficientes (TORNERO; TAUT, 2010; TAUT et al., 2011b).

Siguiendo con la validez consecuencial, se han analizado consecuencias de dispositivos relacionados como la Asignación de Excelencia Pedagógica (AEP), un programa voluntario que busca acreditar -mediante una prueba escrita y un portafolio- las competencias y conocimientos de los docentes, y cuya acreditación implica incentivos económicos y reconocimientos sociales. Araya et al. (2011) entrega evidencia que sólo respalda consecuencias a nivel individual entre quienes logran la acreditación, como mayor autoestima y valoración del incentivo económico, empero a nivel organizacional se identifica escasa difusión de prácticas y poca participación de los docentes certificados en la gestión pedagógica que coordinan los directores y administradores escolares.

Como anticipamos la agenda investigativa incluye estudios sobre validez convergente y discriminante. Los hallazgos de estos estudios indican que: existe moderada evidencia convergente de los resultados de la evaluación cuando se considera el desempeño en la AEP como criterio de validación (TAUT et al., 2011a); los instrumentos evaluativos distinguen consistentemente a profesores ubicados en niveles extremos de desempeño, exhibiendo mayor capacidad discriminatoria el portafolio, pero no se informa sobre la capacidad discriminatoria de los niveles intermedios (SANTELICES; TAUT, 2011; TAUT et al., 2012); finalmente, mediante medidas de valor agregado se encuentra evidencia que respalda la relación positiva, aunque moderada, entre el desempeño docente y mejores resultados en pruebas estandarizadas, controlando variables individuales, socioeconómicas, tamaño de curso y género (TAUT; SUN, 2014; TAUT et al., 2014).

Siguiendo el juicio de los autores de esta agenda investigativa, la evidencia publicada entre 2010 y 2014 respalda una validez parcial del Sistema de Evaluación Docente. Con más detalle, las publicaciones pesquisadas entregan evidencia sobre la validez de contenido y de estructura interna de los instrumentos, a la vez que proporcionan resultados favorables de validez convergente y discriminante, aunque obtenida principalmente del portafolio. Empero, los estudios de validez consecuencial reportan hallazgos referidos a un logro sólo parcial de las consecuencias esperadas, heterogeneidad en las expectativas de los actores involucrados y resistencias por parte del profesorado.

\section{Consideraciones Finales}

La presente revisión de alcance nos ha permitido analizar la producción empírica reciente sobre trabajo docente y NGP en Chile. En este apartado, comenzaremos planteando conclusiones generales derivadas de la revisión, luego discutiremos los principales hallazgos obtenidos, y finalmente propondremos algunas proyecciones para fortalecer una agenda investigativa en la materia.

Una primera conclusión general refiere a la existencia de un corpus incipiente de investigaciones acerca del tema, que se ha desarrollado en paralelo con la creciente promulgación de leyes escolares de tipo gerencial acaecida en Chile durante la última década. Aún más, el proceso de revisión permitió identificar que esta producción empírica se distribuye en cuatro categorías investigativas claramente definidas y que es desarrollada por equipos académicos con una extensa trayectoria en investigaciones sobre trabajo docente y políticas educativas.

Como segunda conclusión, se tiene que las tres primeras categorías identificadas emanan de equipos que comparten perspectivas teóricas y metodológicas, las cuales pueden caracterizarse como 
de carácter crítico y dirigidas a develar los efectos cotidianos que producen las políticas manageriales en contextos socioeducativos reales. En este sentido, parte importante de las publicaciones clasificadas en la segunda y tercera categoría se sustentan en la noción de recontextualización de políticas (BALL, 2015), es decir, asumen que los agentes educativos efectúan procesos de apropiación de los marcos regulatorios mediante su interpretación y traducción en diversas formas de comportamiento, que en muchas ocasiones son inesperadas y contraproducentes. En contraste, la cuarta categoría se diferencia de las anteriores porque es desarrollada desde una perspectiva centrada únicamente en identificar las propiedades científicas de los instrumentos del Sistema Nacional de Evaluación Docente, careciendo de cuestionamientos críticos respecto de los modelos de trabajo promovidos por esta política y sobre su ajuste al quehacer del profesorado. También de forma contrastante, la cuarta categoría se desarrolla, mayormente, sin entablar un debate académico con otros investigadores de la comunidad chilena y con evidente sesgo hacia la literatura estadounidense sobre evaluación educativa y trabajo docente.

En el plano metodológico, constatamos un predominio de estudios cualitativos (35), evidenciándose una diversidad de técnicas como análisis críticos de discurso, estudios documentales y etnografías, que en su mayoría emplean enfoques dinámicos e interpretativos focalizados en relevar la voz de quienes experimentan cotidianamente este tipo de políticas: los profesores ( $v$. g., ASSAÉL et al., 2014). Esta orientación investigativa respalda lo expuesto acerca de la importancia metodológica de las recontextualizaciones, en tanto y en cuanto, proceso clave para comprender el éxito o fracaso de una política del trabajo docente.

A modo de discusión de los principales hallazgos relevamos cinco ideas derivadas de esta revisión. Primeramente, se identifica que las políticas promulgadas acerca de gestión escolar y la profesión docente tipifican una imagen unidimensional del profesor y su trabajo, centrada en una perspectiva técnica, fuertemente regulada por estándares y consecuencias de alto impacto ( $v$. g., CORNEJO et al., 2015). Este hallazgo reafirma evidencia internacional que relaciona consistentemente el gerencialismo con la pérdida de autonomía en el ejercicio profesional, cada vez más constreñido por el cumplimiento de metas y procedimientos estandarizados (BALL, 2003; GLEESON; KNIGHTS, 2006; TSANG; KWONG, 2016; MINCU, 2018).

En segundo lugar, la evidencia acumulada describe una significativa distancia entre el trabajo prescrito en los distintos marcos regulatorios y las condiciones reales en que se ejerce la docencia ( $v$. g., SISTO, 2012). Como ejemplo de esto, los resultados ilustran que, aun cuando el sistema de evaluación docente dispone de instrumentos con una adecuada validez técnica, parte importante de sus consecuencias esperadas no se cumplen o tienden a distorsionarse ( $v . g$., ARAYA et al., 2011). Las investigaciones internacionales aportan sustento a este hallazgo, pues se ha reportado una importante brecha entre los procedimientos y las metas predefinidas por las políticas y el trabajo cotidiano de los profesores, generándose procesos de desafección o carencia de compromiso emocional (KELCHTERMANS, 2005; DE GAULEJAC, 2007).

El tercer hallazgo alude a la relevancia que adquiere la subjetividad docente en los procesos de diseño y puesta en práctica de las políticas (v. g., TORNERO; TAUT, 2010; FARDELLA, 2013). Como adelantamos, la revisión reposicionó la relevancia de la producción de subjetividad en tanto factor clave para comprender el ajuste de las políticas a las condiciones y necesidades de los agentes educativos. En este punto, advertimos una diferencia con la literatura internacional, pues en esta se aprecia una mayor producción sobre algunos procesos subjetivos críticos, como la afectación emocional del profesorado o los relatos identitarios construidos en torno al oficio y su relación con las políticas manageriales (v. g., TSANG; KWONG, 2016). 
Un cuarto hallazgo refiere a que, lejos de generar adhesión voluntaria y procesos de mejoramiento, las tecnologías y dispositivos gerencialistas tienden a provocar efectos contraproducentes, tales como: cuestionamientos y resistencias por su baja legitimidad social y política (v. g., FARDELLA; SISTO, 2015); desmoralización en comunidades educativas vulnerables (v.g., ACUÑA et al., 2014); y quebrantamiento del capital social de los profesores ( $v$. g., MONTECINOS et al., 2014). Al respecto, la literatura internacional concuerda en la ocurrencia de efectos negativos no esperados ante la aplicación de este tipo de políticas, empero sus énfasis se centran más en fenómenos como el estrechamiento curricular y las prácticas de "entrenamiento para la prueba" (DARLING-HAMMOND, 2014; VAN DER SLUIS et al., 2017).

En quinto lugar, se encuentra el hallazgo referido a que el actual diseño de la política docente no incorpora las perspectivas de los educadores ni del gremio magisterial sobre su propio trabajo, constituyéndose en actores ausentes del proceso decisional o, como lo indican algunas publicaciones revisadas, en un ejecutor pasivo del mandato oficial (v.g., ROJAS; LEYTON, 2014). Esta última temática es escasamente mencionada en la producción académica internacional.

De este modo, apreciamos que en general los hallazgos de la literatura chilena sobre trabajo docente y NGP se alinean con los resultados reportados a nivel internacional, no obstante, las diferencias constatadas se relacionarían con la fuerza discursiva e intensidad prescriptiva que ha adquirido la NGP en Chile. Esto es evidenciable en la instalación de una imagen muy nítida de lo que debe ser la profesión docente, como un trabajo individual, competitivo, ajeno a los contextos socioculturales del alumnado, que constriñe los relatos identitarios sobre el trabajo en aspectos más profundos de la subjetividad que los reportados internacionalmente ( $v . g$., HERR, 2015; DE GAULEJAC, 2007). En consecuencia, como hipótesis podemos plantear que las particularidades del modelo educativo chileno, basado en medidas fundamentalistas de mercado y competencia aplicadas durante más de tres décadas, han sido terreno fértil para que las políticas gerencialistas impacten de manera profunda en diversas dimensiones del trabajo y la subjetividad docente.

Finalmente, acerca de las proyecciones para fortalecer una agenda investigativa sobre trabajo docente y NGP en Chile, identificamos seis aspectos a considerar:

- La revisión evidenció que investigaciones centradas sólo en estimar propiedades científicas de instrumentos evaluativos adolecen de significancia para los actores educativos. Por tanto, la investigación de políticas del trabajo docente debe asumir una perspectiva crítica sobre los efectos y la utilidad de las políticas en función de los contextos socioeducativos reales en que se desenvuelve el profesorado;

- Desarrollar investigaciones referidas al diseño y elaboración de políticas del trabajo docente, a fin de evidenciar la correlación de fuerzas en los procesos decisionales e identificar la influencia de los diferentes grupos de interés, entre otros aspectos;

- Profundizar los estudios etnográficos, metodología tratada aún escasamente, lo que aportaría conocimiento relevante acerca de los procesos de recontextualización de políticas;

- Los estudios sobre dimensiones de la politicidad del trabajo docente también requieren mayor atención por parte de los especialistas, pues proporcionarían indicios claves, no sólo sobre las demandas del magisterio, sino también acerca de sus propuestas y su constitución como sujeto colectivo;

- Las investigaciones de subjetividad y trabajo docente requieren avanzar en torno al modo en que los profesores se apropian de los marcos legales derivados de la reciente reforma, que como sabemos incluyó una Ley de Carrera Docente; 
- Por último, una línea de investigación susceptible de desarrollos empíricos en Chile concierne a los procesos psicológicos críticos del trabajo docente, tales como la emoción y la motivación, y su relación con las políticas gerenciales.

En consecuencia, resulta necesario proseguir la tarea investigativa en base al estado actual del conocimiento, pues la producción pesquisada representa aún un corpus incipiente de investigaciones, a la vez que el conjunto de leyes recientemente aprobadas establece un escenario abierto, en el cual los marcos regulatorios basados en la NGP están desplegándose y, por ende, sus efectos son todavía desconocidos.

\section{Notas}

1. Categoría de desempeño establecida en la ley SEP que implicaba posibilidades de cierre de una escuela por bajo rendimiento.

2. Sistema Nacional de Medición de la Calidad Educativa: evaluación censal de tipo estandarizada de los aprendizaje en las asignaturas de Lenguaje y Comunicación; Matemática; Ciencias Naturales; Historia, Geografía y Ciencias Sociales e Inglés.

3. Sistema Nacional de Evaluación de Desempeño (SNED): programa estatal que proporciona un incentivo económico que se asigna a los profesores en función de incrementos en los resultados del SIMCE.

4. En el ámbito de la psicometría, el Alfa de Cronbach refiere a un coeficiente numérico que permite estimar la fiabilidad de una escala de medida o instrumento de medición.

\section{Contribución de los Autores}

Conceptualización de la investigación, Oyarzún C, Cornejo R; Revisión de la literatura, Oyarzún C, Cornejo R; Instrumentos de recolección y análisis de dados, Oyarzún C, Cornejo R; Discusión, Oyarzún C, Cornejo R; Escritura, Oyarzún C, Cornejo R; Corrección de estilo, Oyarzún C, Cornejo R.

\section{Referencias}

ACUÑA, F. Incentivos al trabajo profesional docente y su relación con las políticas de evaluación e incentivo económico individual. Estudios pedagógicos, v. 41, n. 1, p. 7-26, 2015. http://doi. org/10.4067/S0718-07052015000100001

ACUÑA, F. et al. La traducción de los discursos de la política educativa en la cotidianeidad de dos escuelas municipales chilenas: La metáfora médica como vía de análisis. Psicoperspectivas, v. 13, n. 1, p. 46-55, 2014. http://doi.org/10.5027/psicoperspectivas-Vol13-Issue1-fulltext-363

ALVESSON, M. The future of critical management studies. In: BARRY, D.; HANSEN, H. (eds.). The sage handbook of new approaches to organization studies. London: Sage, 2008, p. 13-26.

ANDERSON, G.; COHEN, M. I. Redesigning the identities of teachers and leaders: A framework for studying new professionalism and educator resistance. Education Policy Analysis Archives, v. 23, n. 85, 2015. http://doi.org/10.14507/epaa.v23.2086 
ARAYA, C. et al. Validez consecuencial del programa de asignación de excelencia pedagógica en Chile. Estudios Pedagógicos, v. 37, n. 2, p. 25-42, 2011. http://doi.org/10.4067/S0718-07052011000200001

ASSAÉL, J.; CORNEJO, R. Work regulations and teacher subjectivity in a context of standardization and Accountability Policies in Chile. In: NORMAND, R.; LIU, M.; CARVALHO, L.; ANDRADE, D.; LEVASSEUR, L. (eds.). Education Policies and the Restructuring of the Educational Profession. Beijing: Springer, 2018, p. 245-257.

ASSAÉL, J. et al. Ley SEP en escuelas municipales emergentes: ¿cambios en la identidad docente? Revista de Pedagogía Crítica, v. 11, p. 219-228, 2012. https://doi.org/10.25074/07195532.11.453

ASSAÉL, J. et al. Transformaciones en la cultura escolar en el marco de la implementación de políticas de accountability en Chile. Un estudio etnográfico en dos escuelas clasificadas en recuperación. Estudios Pedagógicos, v. 40, n. 2, p. 7-26, 2014. http://doi.org/10.4067/S0718-07052014000300001 ASSAÉL, J. et al. La crisis del modelo educativo mercantil chileno: Un complejo escenario. Currículo sem Fronteiras, v. 15, n. 2, p. 334-345, 2015.

ÁVALOS, B. Teacher evaluation in Chile: Highlights and complexities in 13 of experience. Teachers and Teaching, v. 24, n. 3, p. 297-311, 2017.

ÁVALOS, B.; DE LOS RÍOS, D. Reform environment and teacher identity in Chile. In: NAPIER, D. B.; MAJHANOVICH S. (eds.). Education, Dominance and Identity. Rotterdam: Sense Publishers, 2013, p. 153-175.

ARKSEY, H.; O'MALLEY, L. Scoping studies: Towards a methodological framework. International Journal of Social Research Methodology, v. 8, n. 1, p. 19-32, 2005. https://doi.org/10.1080/136455 7032000119616

BALL, S. Profesionalismo, gerencialismo y performatividad. Revista Educación y Pedagogía, v. 25, n. 37, p. 87-104, 2003.

BALL, S. What is policy? 21 years later: Reflections on the possibilities of policy research. Discourse: Studies in the cultural politics of education, 2015. http://doi.org/10.1080/01596306.2015.1015279

BALL, S.; YOUDELL, D. La privatización encubierta en la educación pública. Londres: Instituto de Educación/Universidad de Londres, 2008.

BISCARRA, C.; GIACONI, C.; ASSAÉL, J. El docente en la legislación educacional chilena. Psicoperspectivas, v. 14, n. 3, p. 80-92, 2015. Disponible en: https://scielo.conicyt.cl/pdf/psicop/ v14n3/art08.pdf

CAMPOS, H. et al. Metáforas que construyen la política de evaluación e incentivo al desempeño docente en Chile. Teoria \& Sociedade, n. 21, p. 36-57, 2013.

CARRASCO, A. Mecanismos performativos de la institucionalidad educativa en Chile: Pasos hacia un nuevo sujeto cultural. Observatorio Cultural, v. 15, p. 4-10, 2013.

CARVALHO, M. L.; NORMAND, R. Introduction. In: NORMAND, R.; LIU, M.; CARVALHO, L.; ANDRADE, D.; LEVASSEUR, L. (eds.). Education Policies and the Restructuring of the Educational Profession. Beijing: Springer, 2018, p. 1-12. 
CASTILlO, S.; WILLIAMSON, G.; HIDALGO, C. La evaluación del desempeño docente desde la perspectiva de profesores de educación rural. Educación y Educadores, v. 20, n. 3, p. 364-368, 2017. http://doi.org/10.5294/edu.2017.20.3.2

CHEN, J. Understanding teacher emotions: The development of a teacher emotion inventory. Teaching and Teacher Education, v. 55, p. 68-77, 2016.

CHILE. Ministerio de Educación. Ley sobre Evaluación Docente, Ley n· 19.961/2004, 2004. Disponible en: https://www.leychile.cl/Navegar?idNorma=228943. Acceso en: 31 ene. 2019.

CHILE. Ministerio de Educación. Establece Ley de Subvención Escolar, Ley n 20.248/2008, 2008. Disponible en: https://www.leychile.cl/Navegar?idNorma=269001. Acceso en: 31 ene. 2019.

CHILE. Ministerio de Educación. Establece Ley General de Educación, Ley n· 20.370/2009, 2009. Disponible en: https://www.leychile.cl/Navegar?idNorma=1006043\&idVersion=2009-09-12. Acceso en: 31 ene. 2019.

CHILE. Ministerio de Educación. Ley de Calidad y Equidad de la Educación, Ley n 20.501/2011, 2011a. Disponible en: https://www.leychile.cl/Navegar?idNorma=1022346. Acceso en: 31 ene. 2019.

CHILE. Ministerio de Educación. Establece Ley que Crea el Sistema Nacional de Aseguramiento de la Calidad de la Educación Parvularia, Básica y Media y su Fiscalización, Ley n· 20.529/2011, 2011 b. Disponible en: https://www.leychile.cl/Navegar?idNorma=1028635. Acceso en: 31 ene. 2019.

CHILE. Ministerio de Educación. Ley de Inclusión Escolar que Regula la Admisión de los y las Estudiantes, Elimina el Financiamiento Compartido y Prohíbe el Lucro en Establecimientos Educacionales que Reciben Aportes del Estado, Ley n 20.845/2015, 2015. Disponible en: https:// www.leychile.cl/Navegar?idNorma=1078172. Acceso en: 31 ene. 2019.

CHILE. Ministerio de Educación. Ley que Crea el Sistema de Desarrollo Profesional Docente y modifica otras normas, Ley n· 20.903/2016, 2016. Disponible en: https://www.leychile.cl/ Navegar?idNorma=1087343. Acceso en: 31 ene. 2019.

CHILE. Ministerio de Educación. Ley que Crea el Sistema de Educación Pública, Ley n 21.040/2017, 2017. Disponible en: https://www.leychile.cl/Navegar?idNorma=1111237. Acceso en: 31 ene. 2019.

CONTRERAS, D.; RAU, T. Tournament Incentives for Teachers: Evidence from a Scaled-Up Intervention in Chile. Economic Development and Cultural Change, v. 61, n. 1, p. 219-246, 2012. https://doi.org/10.1086/666955

CORNEJO, R. Políticas y reformas escolares: El experimento educativo chileno y su evolución. In: RUIZ, C.; REYES, L.; HERRERA, F. (eds.). Privatización de lo público en el sistema escolar. Chile y la agenda global de educación. Santiago: LOM Editores, 2018, p. 237-263.

CORNEJO, R.; INSUNZA, J. El sujeto docente ausente de las movilizaciones educativas: Un análisis del discurso docente. Psicoperspectivas, v. 12, n. 2, p. 72-82, 2013. http://doi.org/10.5027/ psicoperspectivas-Vol12-Issue2-fulltext-282

CORNEJO, R.; CARO, M. Las preguntas que plantea la ley de Carrera Docente del Gobierno. El Mostrador, Santiago, 7 may. 2015. Disponible en: https://www.elmostrador.cl/noticias/ 
opinion/2015/05/07/las-preguntas-que-plantea-la-ley-de-carrera-docente-del-gobierno/. Acceso en: 31 ene. 2019.

CORNEJO, R. et al. Las prescripciones del trabajo docente en el nuevo marco regulatorio de políticas educativas en Chile. Psicoperspectivas, v. 14, n. 2, p. 72-83, 2015. http://doi.org/10.5027/ psicoperspectivas-vol14-issue2-fulltext-580

DARLING-HAMMOND, L. Standards, assessments and educational policy: Pursuit of genuine accountability. Princeton: Educational Testing Service, 2014.

DE GAULEJAC, V. Gestão como doença social. Ideologia, poder gerencialista e fragmentação social. São Paulo: Idéias \& Letras, 2007.

ELACQUA, G. et al. Short-run effects of accountability pressures on teacher policies and practices in the voucher system in Santiago, Chile. School Effectiveness and School Improvement, v. 27, n. 3, p. 385-405, 2015. http://doi.org/10.1080/09243453.2015.1086383

ETCHEBERRIGARAY, G. et al. Concepciones sobre docencia en el nuevo marco regulatorio del sistema escolar chileno. Revista de Psicología, v. 26, n. 1, p. 1-13, 2017. http://doi. org/10.5354/0719-0581.2017.46693

FALABELLA, A. Do national test scores and quality labels trigger school self-assessment and accountability? A critical analysis in the Chilean context. British Journal of Sociology of Education, v. 37, n. 5, p. 743-760, 2014. https://doi.org/10.1080/01425692.2014.976698

FALABELLA, A. El mercado escolar en Chile y el sugimiento de la Nueva Gestión Pública: El tejido de la política entre la dictadura neoliberal y los gobienros de la centroizquierda (1979 a 2009). Educaçao \& Sociedade, v. 36, n. 132, p. 699-722, 2015. http://doi.org/10.1590/ES0101-73302015152420

FALABELLA, A. ¿Qué aseguran las políticas de aseguramiento de la calidad? Un estudio de casos en distintos contextos escolares. Estudios Pedagógicos, v. 42, n. 1, p. 107-126, 2016. http://doi. org/10.4067/S0718-07052016000100007

FARDELLA, C. Verdades sobre la docencia, efectos y consecuencias subjetivas de la evaluación docente en Chile. Revista de Psicología, v. 21, n. 1, p. 209-222, 2012. http://doi.org/10.5354/0719-0581.2012.19996

FARDELLA, C. Resistencias cotidianas en torno a la institucionalización del modelo neoliberal en las políticas educacionales: El caso de la docencia en Chile. Psicoperspectivas, v. 12, n. 2, p. 83-92, 2013. http://doi.org/10.5027/psicoperspectivas-Vol12-Issue2-fulltext-294

FARDELlA, C.; SISTO, V. Nuevas Regulaciones del trabajo docente en Chile. Discurso, subjetividad y resistencia. Psicologia \& Sociedade, v. 27, n. 1, p. 68-79, 2015. http://doi. org/10.1590/1807-03102015v27n1p068

FERNÁNDEZ, R. et al. Los discursos sobre autonomía del trabajo docente en el nuevo marco regulatorio educativo chileno. Currículo sem Fronteiras, v. 16, n. 2, p. 283-302, 2016.

FERRADA, R. Críticas a las políticas de rendición de cuentas según lo que el profesorado chileno de secundaria considera justo en educación. Revista de la Asociación de Sociología de la Educación, v. 10, n. 3, p. 330-346, 2017. https://doi.org/10.7203/RASE.10.3.9905 
GUERRERO, P. Equidad, justicia y reconocimiento en el trabajo de los profesores/as de las escuelas vulnerables. Trabalho(En)Cena, v.2,n.2,p.98-113,2017.https://doi.org/10.20873/2526-1487V2N2P98 GUERRERO, P.; BALBOA, M.; MIRANDA, G. Sufrimiento y reconocimiento en el trabajo: Un estudio de caso. Teuken Bidikay. v. 8, n. 11, p. 175-190, 2017. https://doi.org/10.33571/teuken.v8n11a9

GEWIRTZ, S.; BALL, S. From 'Welfarism' to 'New Managerialism': Shifting discourses of school headship in the education marketplace. Discourse: Studies in the cultural politics of education, v. 21, n. 3, p. 253-268, 2000.

GLEESON, D.; KNIGHTS, D. Challenging dualism: Public professionalism in "troubled" times. Sociology, v. 40, n. 2, p. 277-295, 2006.

GONZÁLEZ, J. et al. Perspectivas y significados del movimiento nacional de estudiantes secundarios chilenos. Némesis, n. 6, p. 41-48, 2008.

HALL, D. et al. Educational reform and modernization in Europe: The role of national contexts in mediating the new public management. European Educational Research Journal, v. 14, n. 6, p. 487 507, 2015. https://doi.org/10.1177/1474904115615357

HERR, K. Cultivating disruptive subjectivities: Interrupting the new professionalism. Education Policy Analysis Archives, v. 23, n. 86, 2015. http://doi.org/10.14507/epaa.v23.2097

HOLlOWAY, J.; SØRENSEN, T. B.; VERGER, A. Global perspectives on high-stakes teacher accountability policies: An introduction. Education Policy Analysis Archives, v. 25, n. 85, 2017. http://doi.org/10.14507/epaa.25.3325

JARPA, C.; CASTAÑEDA, M. Representaciones sociales frente al proyecto de carrera profesional docente en Chile: Análisis estructural del discurso. Revista Brasileira de Educação, v. 23, p. 1-17, 2018. http://doi.org/10.1590/S1413-24782018230075

KELCHTERMANS, G. Teachers' emotions in educational reforms: Self-understanding, vulnerable commitment and micropolitical literacy. Teaching and Teacher Education, v. 21, n. 8, p. 995-1006, 2005.

LEVAC, D.; COLQUHOUN, H.; O`BRIEN, K. Scoping studies: Advancing the methodology. Implementation Science, v. 5, n. 69, p. 1-9, 2010. https://doi.org/10.1186/1748-5908-5-69

MINCU, M. Overcoming fragmented professionalism? Accountability for improvement in teacher preparation in Italy. In: NORMAND, R.; LIU, M.; CARVALHO, L.; ANDRADE, D.; LEVASSEUR, L. (eds.). Education Policies and the Restructuring of the Educational Profession. Beijing: Springer, 2018, p. 235-244.

MINTROP, R. Neo-Liberal managerialism and professionalization in U.S. Schools. In: NORMAND, R.; LIU, M.; CARVAlHO, L.; ANDRADE, D.; LEVASSEUR, L. (eds.). Education Policies and the Restructuring of the Educational Profession. Beijing: Springer, 2018, p. 189-204.

MONTECINOS, C. et al. Master teachers as professional developers: Managing conflicting versions of professionalism. Educational Management Administration \& Leadership, v. 42, n. 2, p. 275-292, 2014. https://doi.org/10.1177/1741143213502191 
MUNN, Z. et al. Systematic review or scoping review? Guidance for authors when choosing between a systematic or scoping review approach. BMC Medical Research Methodology, v. 18, n. 143, p. 1-7, 2018. https://doi.org/10.1186/s12874-018-0611-x

NORMAND, R. et al. (eds.). Education Policies and the Restructuring of the Educational Profession. Beijing: Springer, 2018.

O'FLAHERTY, J.; PHILLIPS, C. The use of flipped classrooms in higher education: A scoping review. The Internet and Higher Education, v. 25, p. 85-95, 2015. https://doi.org/10.1016/j.iheduc.2015.02.002

OCDE [ORGANIZACIÓN PARA LA COOPERACIÓN Y EL DESARROLLO ECONÓMICOS]. Reviews of National Policies for Education: Chile. Paris: OCDE Publications, 2004.

OCDE [ORGANIZACIÓN PARA LA COOPERACIÓN Y EL DESARROLLO ECONÓMICOS]. Capítulo 3: fortalecer la calidad de la enseñanza y el liderazgo escolar en Chile. Evaluaciones de Políticas Nacionales de Educación. Educación en Chile. Ciudad de México: OCDE Publishing/Fundación SM, 2017.p. 131-171.

QUARESMA, M.; ORELLANA, V. El accountability y su impacto en la labor docente: percepciones de los profesores de liceos públicos de alto rendimiento académico en Chile. Currículo sem Fronteiras, v. 16, n. 2, p. 316-338, 2016.

REYES, I.; AKKARI, A. La privatización de la educación en Chile: análisis de los discursos del profesorado y de la dirección de los centros sobre la calidad de la educación y la rendición de cuentas. Revista de la Asociación de Sociología de la Educación, v. 10, n. 3, p. 363-380, 2017. https://doi. org/10.7203/RASE.10.3.9891

ROJAS, M. T.; LEYTON, D. The new teacher subjectivity: Construction of teachers' subjectivities at the beginning of the Preferential School Voucher's implementation in Chile. Estudios Pedagógicos, v. 40, número especial, p. 205-221, 2014. https://doi.org/10.4067/S0718-07052014000200012

ROA-TAMPE, K. La evaluación docente bajo la óptica del desarrollo profesional: El caso chileno. Educación y Educadores, v. 20, n. 1, p. 41-61, 2017. http://doi.org/10.5294/edu.2017.20.1.3

RUFFINELLI, A. Ley de desarrollo profesional docente en Chile: De la precarización sistemática a los logros, avances y desafíos pendientes para la profesionalización. Estudios Pedagógicos, v. 42, n. 4, p. 261-279, 2016. https://doi.org/10.4067/S0718-07052016000500015

SANTELICES, M. V. et al. Consecuencias a Nivel Local de un Sistema de Evaluación de Profesores: El Caso de Chile. Estudios Pedagógicos, v. 39, n. 2, p. 299-328, 2013. http://doi.org/10.4067/ S0718-07052013000200019

SANTELICES, M. V.; TAUT, S. Convergent validity evidence regarding the validity of the Chilean standards-based teacher evaluation system. Assessment in Education: Principles, Policy \& Practice, v. 18, n. 1, p. 73-93, 2011. https://doi.org/10.1080/0969594X.2011.534948

SANTIAGO, P. et al. Teacher Evaluation in Chile 2013. OECD Reviews of Evaluation and Assessment in Education. Paris: OECD Publishing, 2013.

SISTO, V. Nuevo profesionalismo y profesores: Una reflexión a partir del análisis de las actuales políticas de 'profesionalización' para la educación en Chile. Signo y Pensamiento, v. 31, n. 59, p. 178-192, 2011. 
SISTO, V. Identidades desafiadas: individualización, managerialismo y trabajo docente en el Chile actual. PSYKHE, v. 21, n. 2, p. 35-46, 2012. http://doi.org/10.7764/psykhe.21.2.542

SISTO, V.; FARDELLA, C. Nuevas Políticas Públicas, Epocalismo e Identidad: El caso de las políticas orientadas a los docentes en Chile. Revista de Estudios Universitarios, v. 37, n. 1, p. 123-141, 2011.

SISTO, V.; MONTECINOS, C.; AHUMADA, L. Disputas de significado e identidad: la construcción local del trabajo docente en el contexto de las políticas de evaluación e incentivo al desempeño en Chile. Universitas Psychologica, v. 12, n. 1, p. 173-184, 2013. https://doi.org/10.11144/Javeriana. upsy12-1.dsic

SOTO, R. et al. Entre la efectividad y los afectos: Nuevos docentes en tiempos de Nuevo Management Público. Athenea Digital. Revista de Pensamiento e Investigación Social, v. 16, n. 3, p. 3-19, 2016. https://doi.org/10.5565/rev/athenea.1528

TAUT, S.; SUN, Y. The Development and Implementation of a National, Standards-based, Multimethod Teacher Performance Assessment System in Chile. Education Policy Analysis Archives, v. 22, n. 71, 2014. http://doi.org/10.14507/epaa.v22n71.2014

TAUT, S.; SANTELICES, V.; MANZI, J. Capítulo 6: Estudios de validez de la Evaluación Docente. In: MANZI, J.; GONZÁLEZ, R.; SUN, Y. (eds.). La evaluación docente en Chile. Santiago: MIDE UC, 2011a. ,p. 157-175.

TAUT, S.; SANTELICES, M. V.; STECHER, B. Validation of a National Teacher Assessment and Improvement System. Educational Assessment, v. 17, p. 163-199, 2012. http://doi.org/10.1080/106 27197.2012.735913

TAUT, S. et al. Theory underlying a national teacher evaluation program. Evaluation and Program Planning, v. 33, n. 4, p. 477-486, 2010. https://doi.org/10.1016/j.evalprogplan.2010.01.002

TAUT, S. et al. Perceived effects and uses of the national teacher evaluation system in Chilean elementary schools. Studies in Educational Evaluation, v. 37, n. 4, p. 218-229, 2011b. https://doi. org/10.1016/j.stueduc.2011.08.002

TAUT, S. et al. Teacher performance and student learning: linking evidence from two national assessment programmes. Assessment in Education: Principles, Policy \& Practice, v. 23, n. 1, p. 53-74, 2014. https://doi.org/10.1080/0969594X.2014.961406

TORNERO, B.; TAUT, S. A mandatory, high-stakes national teacher evaluation system: Perceptions and attributions of teachers who actively refuse to participate. Studies in Educational Evaluation, v. 36, p. 132-142, 2010. https://doi.org/10.1016/j.stueduc.2011.02.002

TSANG, K. A Review of Current Sociological Research on Teachers' Emotions: The way forward. British Journal of Education, Society \& Behavioural Science, v. 4, n. 2, p. 1-15, 2014. https://doi. org/10.9734/BJESBS/2014/6898

TSANG, K.; KWONG, T. Emotional experience of $\mathrm{Caam}^{2}$ in teaching: Power and interpretation of teachers' work. Frontiers in Psychology, v. 7, p. 1-11, 2016. https://doi.org/10.3389/fpsyg.2016.01400

VAILLANT, D. La gobernanza educativa y los incentivos docentes: los casos de Chile y Uruguay. Revista 
Uruguaya de Ciencia Política, v. 21, n. 1, p. 119-141, 2012.

VAILLANT, D.; GONZALEZ-VAILLANT, G. Within the teacher evaluation policies black box: two case studies. Teacher Development, v. 21, n. 3, p. 404-421, 2016. https://doi.org/10.1080/13664530 .2016 .1259649

VAN DERSLUIS, M.; REEZIGT, G.; BORGHANS, L.Implementing new public management in educational policy. Educational Policy, v. 31, n. 3, p. 303-329, 2017.https://doi.org/10.1177\%2F0895904815598393

VEGA, J.; GALAZ, A. Evidencias para una transformación y complejización del modelo chileno de evaluación docente. Educação e Pesquisa, v. 41, n. 1, p. 171-183, 2015. http://doi.org/10.1590/ S1517-97022015011985

VERGER, A.; NORMAND, R. Nueva Gestión Pública y educación: Elementos teóricos y conceptuales para el estudio de un modelo de reforma educativa global. Educaçao \& Sociedade, v. 36, n. 132, p. 599-622, 2015. http://doi.org/10.1590/ES0101-73302015152799

\section{Sobre los Autores}

Cristian Oyarzún Maldonado es psicólogo por la Universidad de Santiago de Chile, Magíster en Ciencias Sociales mención Sociología de la Modernización por la Universidad de Chile y estudiante del Doctorado en Psicología de la Universidad de Chile. Su principal línea de investigación refiere al estudio de las políticas de privatización educativa y sus efectos prácticos en contextos socioeducativos reales.

Rodrigo Cornejo Chávez es psicólogo y Doctor en Psicología por la Universidad de Chile. Actualmente se desempeña como Profesor Asociado de la Facultad de Ciencias Sociales de la Universidad de Chile y es Investigador del Observatorio Chileno de Políticas Educativas (OPECH), de la misma universidad. Sus líneas de investigación han estado principalmente ligadas a trabajo docente, políticas educativas, movimientos sociales por la educación y estudios críticos del discurso. 